\title{
HIGH-TEMPERATURE OXIDATION BEHAVIOR AND KINETICS OF FORGED 12Cr-MoVW STEEL
}

\begin{abstract}
The oxidation kinetics of forged $12 \mathrm{Cr}-\mathrm{MoVW}$ steel was investigated in an air $\left(\mathrm{N}_{2}+\mathrm{O}_{2}\right)$ atmosphere at 873-1073 $\mathrm{K}(\Delta 50 \mathrm{~K})$ using thermogravimetric analysis. The oxidized samples were characterized using X-ray diffraction, and the surface and crosssectional morphologies were examined using scanning electron microscopy coupled with energy-dispersive X-ray spectroscopy. The forged $12 \mathrm{Cr}-\mathrm{MoVW}$ steel samples exhibited parabolic behavior and a low oxidation rate compared with their as-cast counterparts. A protective oxide layer was uniformly formed at relatively low temperature ( $\leq 973 \mathrm{~K})$ for the forged samples, which thus exhibited better oxidation resistance than the as-cast ones. These oxides are considered solid-solution compounds such as $(\mathrm{Fe}, \mathrm{Cr})_{2} \mathrm{O}_{3}$.

Keywords: ferritic/martensitic stainless steels, 12Cr-MoVW steel, forging, oxidation kinetics, oxide layer
\end{abstract}

\section{Introduction}

Since ultra-supercritical (USC) plants were introduced in the late $1990 \mathrm{~s}$, ferritic/martensitic stainless steels have been used as structural materials for components in gas turbines and thermal power plants. These steels have also been used for the rotors, casing valves, tubes, and pipes of USC turbines because of their excellent mechanical and high-temperature creep properties and better price competitiveness compared with austenitic stainless steel $[1,2]$.

The maximum service temperature of these steels is estimated to be approximately $893 \mathrm{~K}$. For components that require oxidation/corrosion resistance at high temperature, $12 \% \mathrm{Cr}$ steels have been primarily used because they provide better oxidation resistance than 9\% Cr steels [3-5]. As superior mechanical and creep properties are required for 500-MW USC facilities of medium-to-large size with extreme operating temperature $(866 \mathrm{~K})$ and pressure $(25 \mathrm{MPa})$, the $12 \% \mathrm{Cr}$ steels used in supercritical (SC) plants have been modified by adding various alloying elements. One of the commercially available alloys in this class of steels is $12 \mathrm{Cr}-\mathrm{MoVW}$ steel [5]. This alloy was developed by adding Mo, V, and $\mathrm{W}$ to AISI 410 stainless steel to increase the creep rupture strength $[1,6,7]$.

However, $12 \% \mathrm{Cr}$ steels are difficult to forge because of the high content of alloy elements. A processing technique using a dynamic material model is used to optimize the workability and to evaluate the thermal deformation mechanisms of a wide range of metal materials [8-10]. To date, many studies [11-13] have focused on the heat-treatment process, mechanical properties, fracture mechanism, and fatigue of $12 \% \mathrm{Cr}$ steels; however, the oxidation behavior after hot deformation has drawn little attention.

The present research was aimed at elucidating the effect of hot forging on the oxidation characteristics of $12 \mathrm{Cr}-\mathrm{MoVW}$ steel. Special emphasis was placed on a detailed examination of the oxide scale to understand the kinetics of and role of the structure in determining the oxidation rate.

\section{Experimental methods}

The chemical composition of the $12 \mathrm{Cr}-\mathrm{MoVW}$ steel used in this study (B50A951A1, SeAh Special Steel Corp., Korea) is listed in Table 1. The as-received specimens were normalized at $1313 \mathrm{~K}$ for $3 \mathrm{~h}$, quenched in oil, and then tempered at $953 \mathrm{~K}$ for $7 \mathrm{~h}$. The heat-treated (as-cast) samples were homogenized at $1373 \mathrm{~K}$ for $3 \mathrm{~h}$ and finally hot forged to achieve $35 \%$ reduction of area. Optical micrographs (OM) of the starting microstructures of the as-cast and forged samples are shown in Fig. 1.

TABLE 1

Chemical composition (wt. \%) of the investigated steel

\begin{tabular}{|c|c|c|c|c|c|c|c|c|c|c|}
\hline \hline \multicolumn{10}{|c|}{ Chemical composition (wt. \%) } \\
\hline $\mathbf{C}$ & $\mathbf{S i}$ & $\mathbf{M n}$ & $\mathbf{P}$ & $\mathbf{S}$ & $\mathbf{N i}$ & $\mathbf{C r}$ & $\mathbf{M o}$ & $\mathbf{C u}$ & $\mathbf{V}$ & $\mathbf{W}$ \\
\hline .205 & .266 & .775 & .0185 & .0018 & .661 & 11.650 & 1.078 & .156 & .255 & 1.050 \\
\hline
\end{tabular}

\footnotetext{
* DEPARTMENT OF MATERIALS SCIENCE AND ENGINEERING, PUSAN NATIONAL UNIVERSITY, BUSAN, REPUBLIC OF KOREA

** MATERIAL ANALYSIS LABORATORY, DEA-IL CORPORATION, ULSAN, REPUBLIC OF KOREA

*** KOREA INSTITUTE OF INDUSTRIAL TECHNOLOGY, BUSAN, REPUBLIC OF KOREA

**** SOCIAL ENTERPRISE, PUSAN NATIONAL UNIVERSITY, BUSAN, REPUBLIC OF KOREA

\# Corresponding author: yhpark@pusan.ac.kr
} 
1100
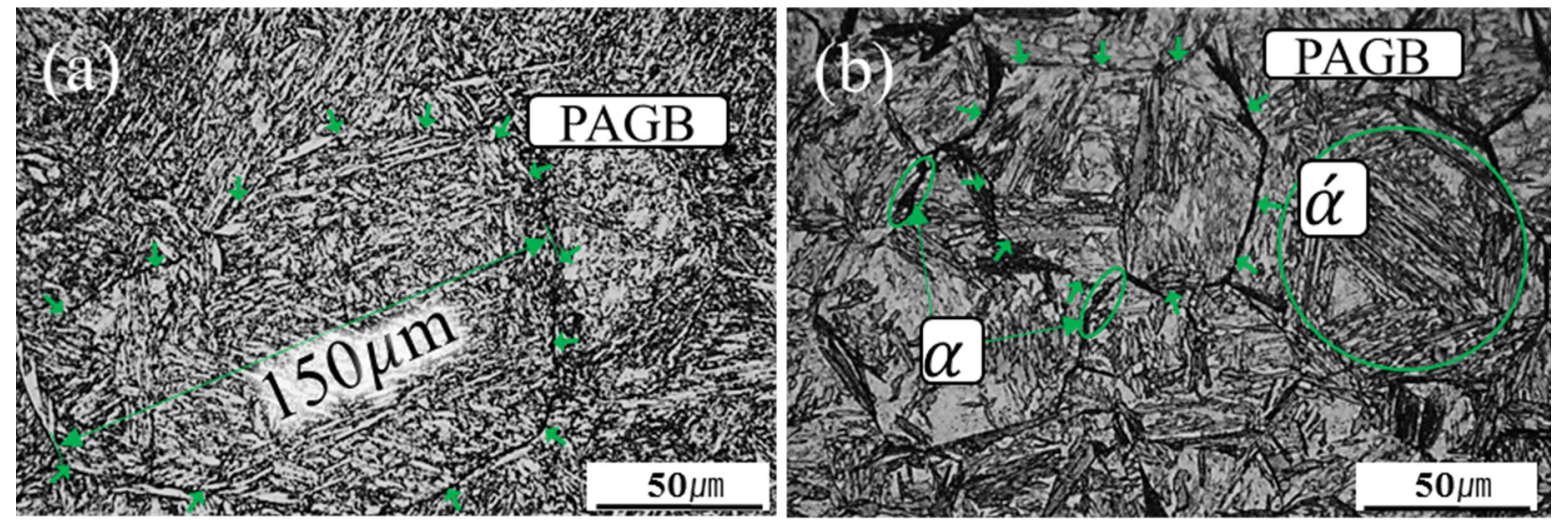

Fig. 1. Optical micrographs of as-cast (a) and forged (b) 12Cr-MoVW steel used in this investigation

For the oxidation test, the specimens were cut into cubes with dimensions of $2.5 \times 2.5 \times 2.5 \mathrm{~mm}^{3}$. All the specimens were ground using $2400 \# \mathrm{SiC}$ paper and ultrasonically cleaned in distilled water and ethanol for 10 min before being weighed. Isothermal oxidation experiments at $873-1073 \mathrm{~K}(\Delta 50 \mathrm{~K})$ for $60 \mathrm{~h}$ were performed using thermogravimetric analysis (TGA, TG/DTA 7300, Seiko, Japan) in an air $\left(\mathrm{N}_{2}+\mathrm{O}_{2}\right)$ atmosphere. The heating rate was $10 \mathrm{~K} / \mathrm{min}$ for all the specimens. The oxide phases were identified using X-ray diffraction (XRD, Rigaku Ultima IV, Japan). The surface and cross-sectional morphologies of the oxidized samples were characterized using field-emission scan- ning electron microscopy (FE-SEM, TESCAN MIRA 3, Czech Republic) coupled with energy-dispersive X-ray spectroscopy (EDS) operating in back-scattered electron (BSE) mode.

\section{Results and discussion}

The oxidation rates of the as-cast and forged $12 \mathrm{Cr}-\mathrm{MoVW}$ steel in the temperature range of $873-1073 \mathrm{~K}$ are plotted in Fig. 2, clearly demonstrating the temperature-dependent oxidation kinetics. The oxidation kinetics were evaluated using the

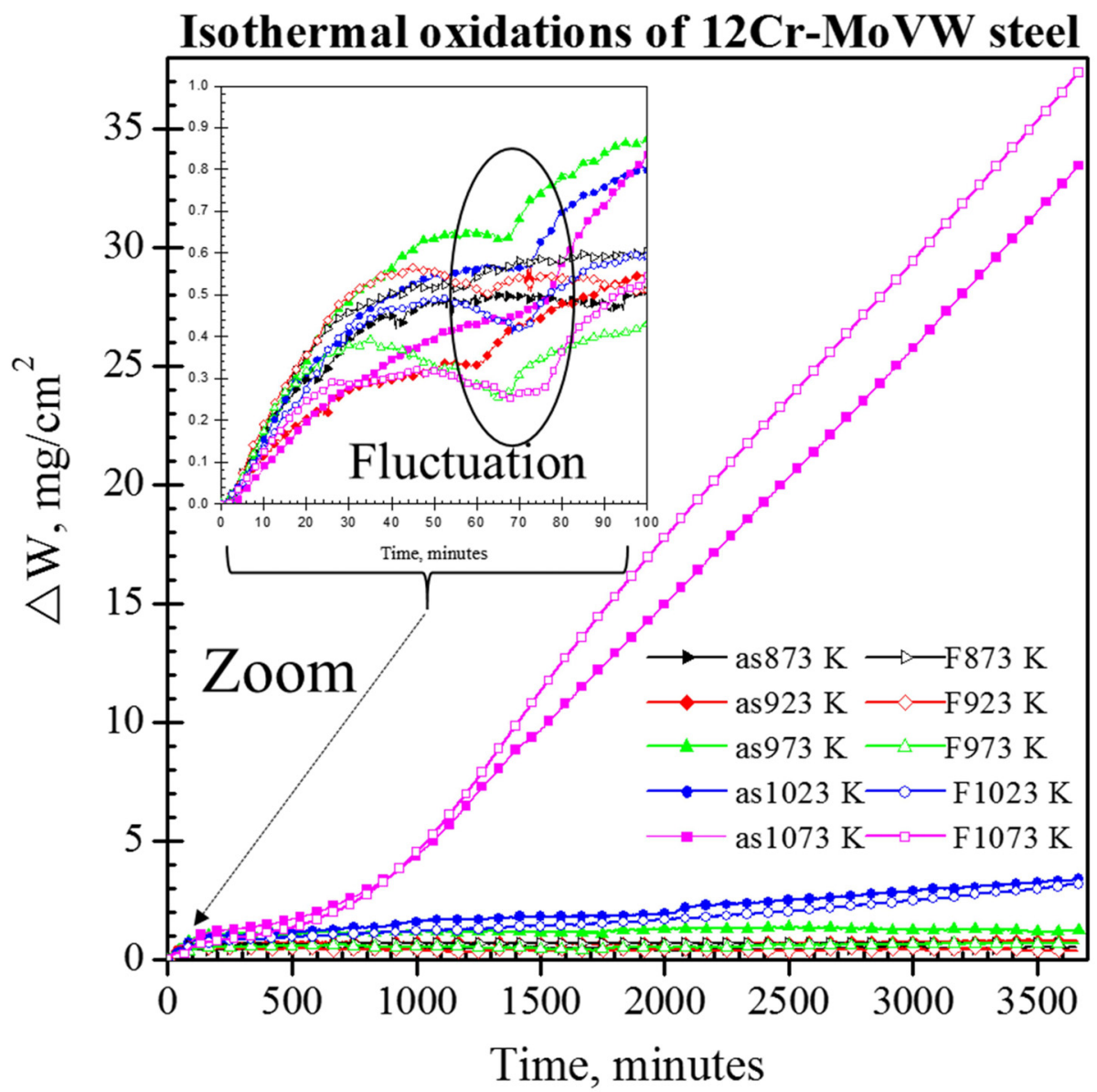

Fig. 2. $\Delta \mathrm{W}$ versus time curves for the as-cast and forged materials exposed to air at 873-1073 $\mathrm{K}(\Delta 50 \mathrm{~K})$ for $60 \mathrm{~h}$ (as: as-cast; $\mathrm{F}$ : forged) 
parabolic rate law $(\Delta \mathrm{W} / \mathrm{A})^{2}=\mathrm{k}_{\mathrm{p}} \cdot \mathrm{t}$, where $(\Delta \mathrm{W} / \mathrm{A})$ is the weight gain $\left(\mathrm{g} / \mathrm{cm}^{2}\right), \mathrm{k}_{\mathrm{p}}$ is the parabolic rate constant $\left(\mathrm{g}^{2} / \mathrm{cm}^{4} \cdot \mathrm{min}^{-1}\right)$, and $\mathrm{t}$ is the oxidation time $(\mathrm{min})[14,15]$. The $\Delta \mathrm{W}$ and $\mathrm{k}_{\mathrm{P}}$ values are summarized in Table 2. The overall oxidation rates of the as-cast specimens are much higher than the forged ones.

The oxidation characteristics between $873 \mathrm{~K}$ and $973 \mathrm{~K}$ indicate parabolic behavior and low oxidation rates with no measurable increase. The enlarged inset in Fig. 2 shows the initial slope of the curves, where fluctuations of $\Delta \mathrm{W}$ in the forged specimens are observed at intermediate temperatures between the heating and isothermal temperatures. This phenomenon is attributed to the martensite phase formed in the forged specimens.

At high temperature $(>973 \mathrm{~K})$, linear behavior at the beginning with a "breakaway" model [16] is observed in both the as-cast and forged specimens after certain incubation times. The incubation time decreased as the oxidation temperature increased
TABLE 2

$\Delta \mathrm{W}$ and $\mathrm{k}_{\mathrm{P}}$ for each isothermal oxidation in air at 873-1073 $\mathrm{K}$ for 60 $h$ and activation energy from Arrhenius plot of $k_{P}$ for oxidation of the as-cast and forged $12 \mathrm{Cr}-\mathrm{MoVW}$ steel specimens

\begin{tabular}{|c|c|c|c|}
\hline Sample & $\begin{array}{c}\Delta W \\
\left(\mathbf{m g} / \mathrm{cm}^{2}\right)\end{array}$ & $\begin{array}{c}\mathrm{K}_{\mathrm{P}} \\
\left(\mathrm{g}^{2} \cdot \mathrm{cm}^{-4} \mathrm{~s}^{-1}\right)\end{array}$ & $\begin{array}{l}\text { Q (oxid.) } \\
\text { (KJ/mol) }\end{array}$ \\
\hline As873 K & 0.5411 & $1.6 \mathrm{E}-13$ & \multirow{5}{*}{379} \\
\hline As923 K & 0.8060 & $7.9 \mathrm{E}-13$ & \\
\hline As973 K & 1.2282 & $3.1 \mathrm{E}-12$ & \\
\hline As1023 K & 3.4100 & $4.9 \mathrm{E}-11$ & \\
\hline As $1073 \mathrm{~K}$ & 33.5800 & 4.9E-09 & \\
\hline F873 K & 0.6833 & $2.7 \mathrm{E}-13$ & \multirow{5}{*}{387} \\
\hline F923 K & 0.3812 & $1.7 \mathrm{E}-13$ & \\
\hline F973 K & 0.6721 & $9.8 \mathrm{E}-13$ & \\
\hline $\mathrm{F} 1023 \mathrm{~K}$ & 3.2103 & $4 \mathrm{E}-11$ & \\
\hline F1073 K & 37.4716 & $6.3 \mathrm{E}-09$ & \\
\hline
\end{tabular}
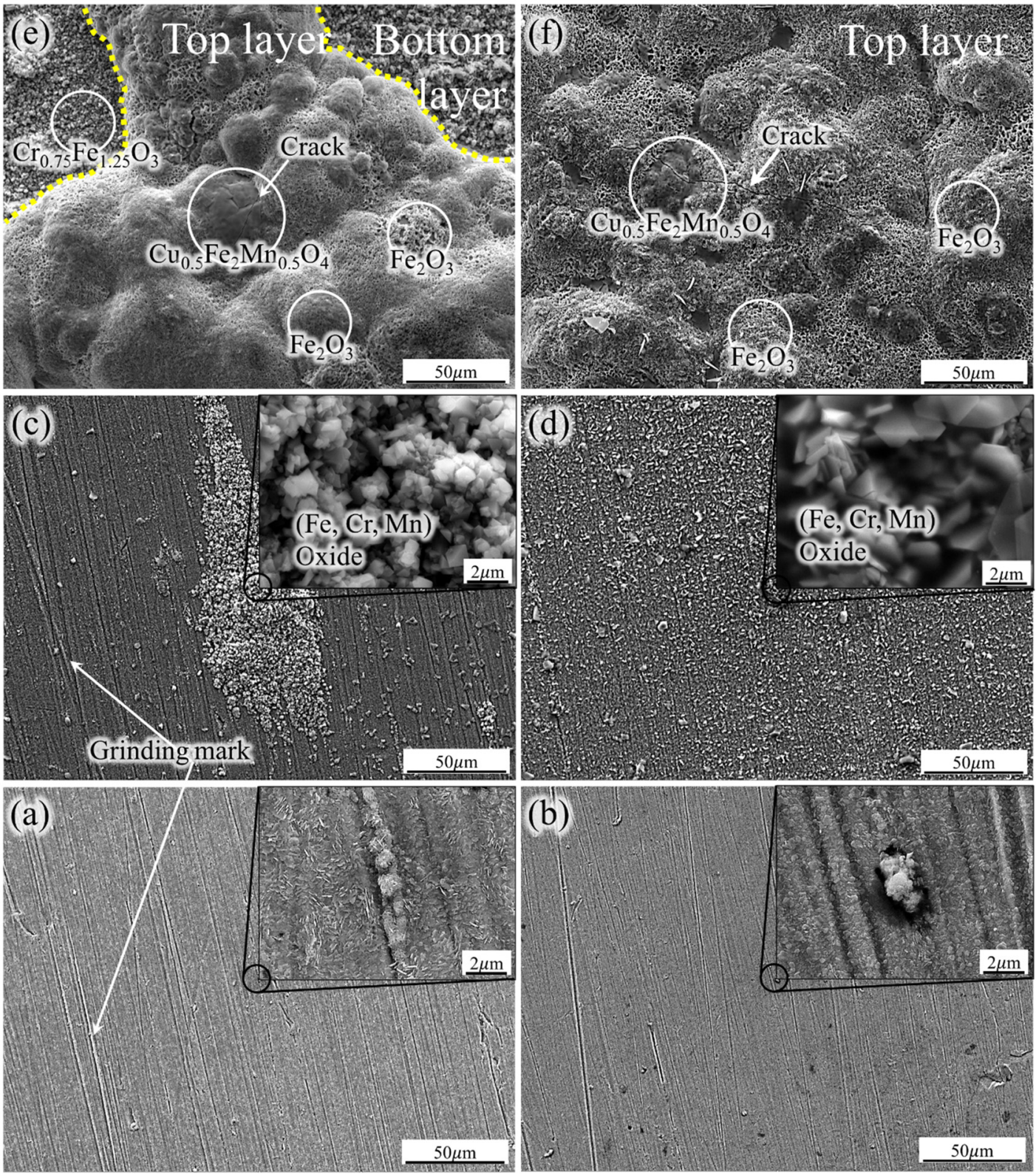

Fig. 3. SEM micrographs of surface morphology of the oxide scales after oxidation in air for $60 \mathrm{~h}$ at $873 \mathrm{~K}$ (a), $973 \mathrm{~K}$ (c), and $1073 \mathrm{~K}$ (e) for the as-cast $12 \mathrm{Cr}-\mathrm{MoVW}$ steel and $873 \mathrm{~K}$ (b), $973 \mathrm{~K}$ (d), and $1073 \mathrm{~K}$ (f) for the forged $12 \mathrm{Cr}-\mathrm{MoVW}$ steel 
from approximately $900 \mathrm{~min}$ at $1023 \mathrm{~K}$ to $2200 \mathrm{~min}$ at $1073 \mathrm{~K}$. The oxidation rates increased continuously with oxidation time.

The activation energy for the forged specimens was calculated to be $387 \mathrm{~kJ} / \mathrm{mol}$ from an Arrhenius plot of the parabolic constants determined from 873 to $1073 \mathrm{~K}$, as listed in Table 2 .

Fig. 3 presents SEM images of the surface morphology of the oxide scales formed on the as-cast and forged materials exposed to air at $873-1073 \mathrm{~K}$ for $60 \mathrm{~h}$. The surface morphology of the specimens in air after $60 \mathrm{~h}$ depended on temperature, consistent with the oxidation kinetics. As observed in Figs. 3(a-d), at relatively low temperature ( $\leq 973 \mathrm{~K}$ ), a flat and thin oxide scale $(\leq 2 \mu \mathrm{m})$ formed that could not cover the grooves resulting from grinding. The oxides formed on the as-cast specimens shown in Fig. 3(c) are observed to be preferentially parallel to the grinding marks, whereas those formed on the forged specimens in Fig. 3(d) are uniformly dispersed. It can be considered that the microstructure of the forged specimens increased the diffusivity of oxygen in the substrate. The oxide nodules formed at $973 \mathrm{~K}$ mostly consisted of ( $\mathrm{Fe}, \mathrm{Cr}, \mathrm{Mn}$ ) oxides in both the as-cast and forged specimens. The XRD patterns in Fig. 4 identify the oxides as $(\mathrm{Mn}, \mathrm{Fe})(\mathrm{V}, \mathrm{Cr})_{2} \mathrm{O}_{4}$. Identification of the oxide compound of $\mathrm{Fe}, \mathrm{Cr}$ and $\mathrm{Mn}$ is complex because these oxides have similar crystal structures and lattice parameters $[17,18]$. Most of the oxide compounds were $\mathrm{Mn}-\mathrm{Cr}$ and $\mathrm{Fe}-\mathrm{Cr}$ oxides.

At very high temperature $(1073 \mathrm{~K})$, the surface was completely covered by oxide nodules in both the as-cast and forged states. The morphology of $\mathrm{Fe}_{2} \mathrm{O}_{3}$ (hematite) predominantly observed in Figs. 3(e-f) indicates that the specimens are covered by porous oxides. The oxide layers in the as-cast state are divided into two layers. The bottom layer in Fig. 3(e) is a flat oxide scale (Fe-Cr oxide) and corresponds to a corundum-type oxide, $\mathrm{Cr}_{0.75} \mathrm{Fe}_{1.25} \mathrm{O}_{3}$, according to the XRD results in Fig. 4(a). The top layer in Fig. 3(e) is mainly composed of $\mathrm{Fe}_{2} \mathrm{O}_{3}$ and a small amount of $\mathrm{Cu}_{0.5} \mathrm{Fe}_{2} \mathrm{Mn}_{0.5} \mathrm{O}_{4}$. Based on these results, it appears that the oxidation continuously progressed non-protectively by propagating along the cracks of $\mathrm{Cu}_{0.5} \mathrm{Fe}_{2} \mathrm{Mn}_{0.5} \mathrm{O}_{4}$. Unlike the ascast specimens oxidized at $1073 \mathrm{~K}$, the forged ones in Fig. 3(f) only consisted of one layer of $\mathrm{Fe}_{2} \mathrm{O}_{3}$ and $\mathrm{Cu}_{0.5} \mathrm{Fe}_{2} \mathrm{Mn}_{0.5} \mathrm{O}_{4}$ (the top layer in the as-cast state), indicating that the non-protective behavior was promoted even more than in the as-cast specimens. This finding corresponds well with the higher $\Delta \mathrm{W}$ values of the forged specimens due to the breakaway oxidation. The oxidation resistance of heat-resistant steels primarily relies on the amount of $\mathrm{Cr}$ content. $\mathrm{Cr}$ forms a protective oxides which are carried out as a barrier to the breakaway behavior. At $1073 \mathrm{~K}$, it can be proposed that a method of adding $\mathrm{Cr}$ originally help the oxidation resistance avoid the breakaway behavior by migrating the cationic $\mathrm{Cr}$ atoms from the substrate. In addition, making ultrafine grains near surface are thought to improve the oxidation resistance by producing the abundant grain boundary density.

Figs. 5(a-d) present cross-sectional BSE images of the samples at 873-1073 K, revealing the temperature dependence of the morphologies; the corresponding EDS line scans are presented in Fig. 6. An extremely thin protective oxide scale formed at $873 \mathrm{~K}$, as observed in Figs. 5(a-b), indicating that both the as-cast
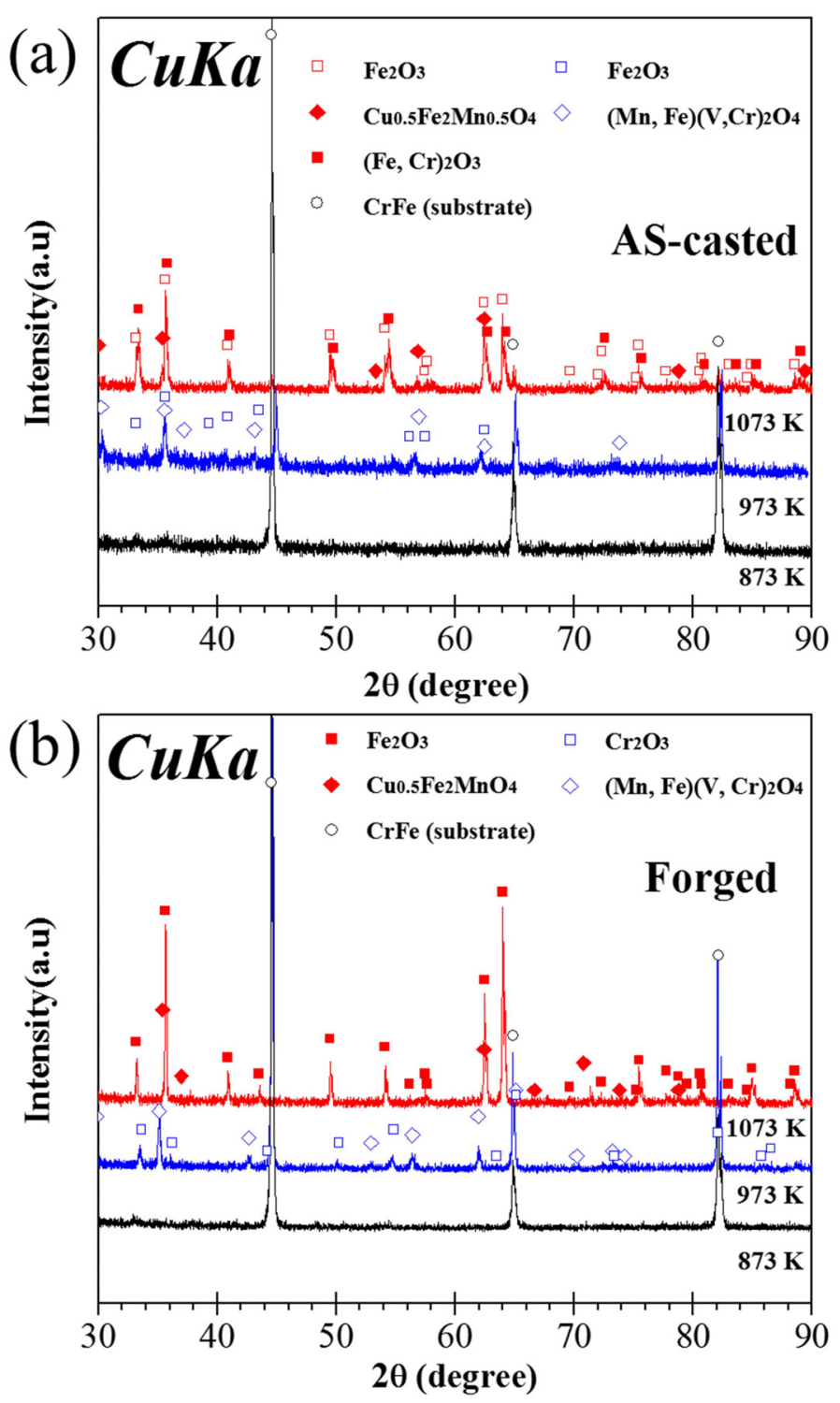

Fig. 4. XRD patterns of the oxide scales formed on the as-cast (a) and forged (b) $12 \mathrm{Cr}-\mathrm{MoVW}$ steel at $873-1073 \mathrm{~K}$ for $60 \mathrm{~h}$ in air

and forged specimens were barely oxidized. The oxide layers at $973 \mathrm{~K}$ in Figs. 5(c-d) are thicker and mainly consisted of $(\mathrm{Cr}$, $\mathrm{Mn})$ oxides. The solid-solution compounds such as $(\mathrm{Fe}, \mathrm{Cr})_{2} \mathrm{O}_{3}$ observed in the forged specimens oxidized at $973 \mathrm{~K}$ are considered to have formed because of solidification between the $\mathrm{Cr}_{2} \mathrm{O}_{3}$ and $\mathrm{Fe}_{2} \mathrm{O}_{3}$ identified in Fig. 4(b) because these compounds are soluble in each other. At very high temperature $(1073 \mathrm{~K})$, the oxide layers in both the as-cast and forged specimens consisted of two layers, with thicknesses greater than $50 \mu \mathrm{m}$, as observed in Figs. 5(e-f).

This result indicates that the weak CrFe peaks in Fig. 4 for the sample oxidized at $1073 \mathrm{~K}$ originate from the thick oxide layer, which can absorb the X-ray signal from the substrate. Voids are also observed in the outer layer, which included Fe-rich oxide. The EDS line scans through the two layers in Figs. 6(e-f) indicate that the outer layer consisted of Fe-rich oxides, whereas the inner layer mainly consisted of (Fe, $\mathrm{Cr}, \mathrm{Mn})$ oxides. Segrega- 

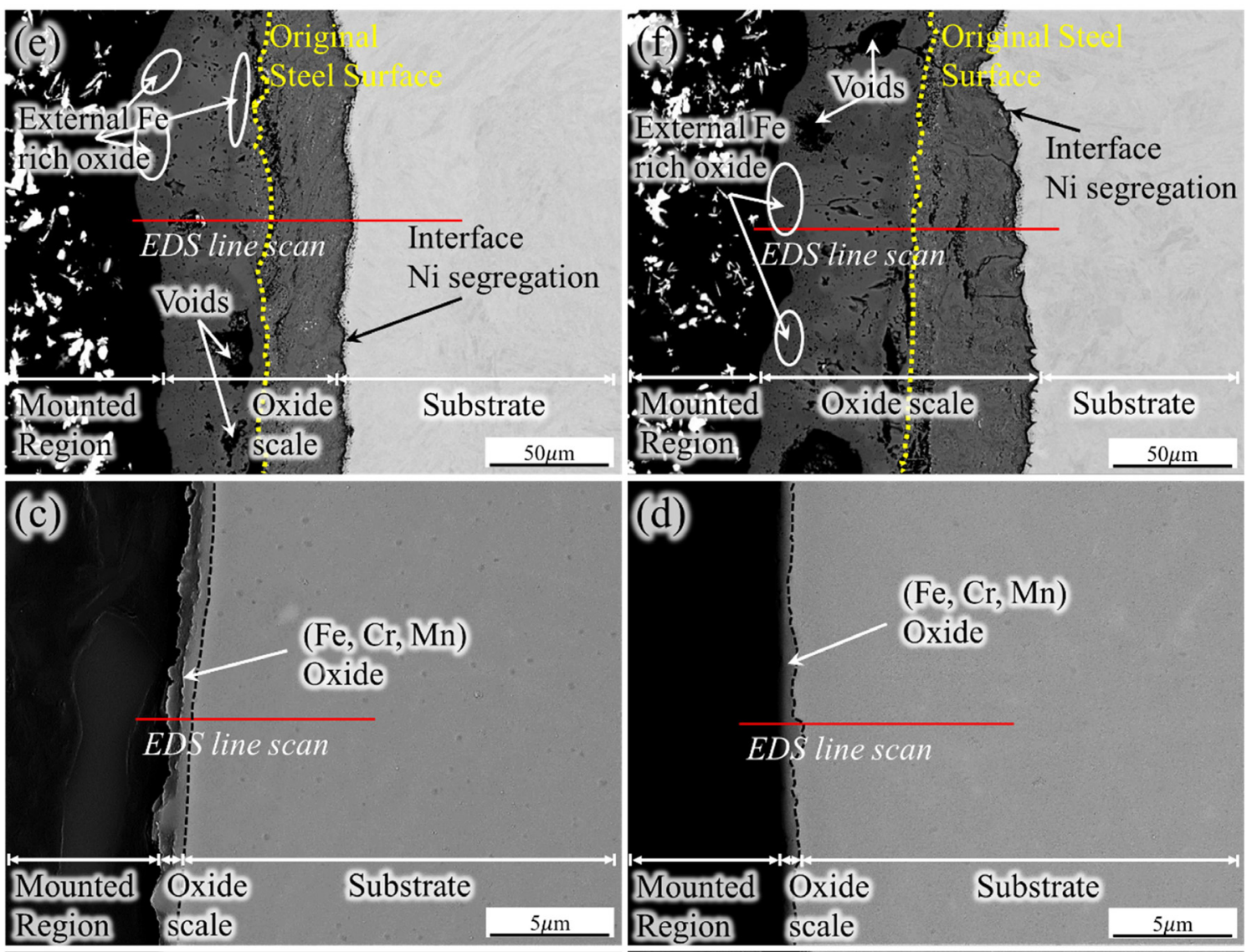

Region scale
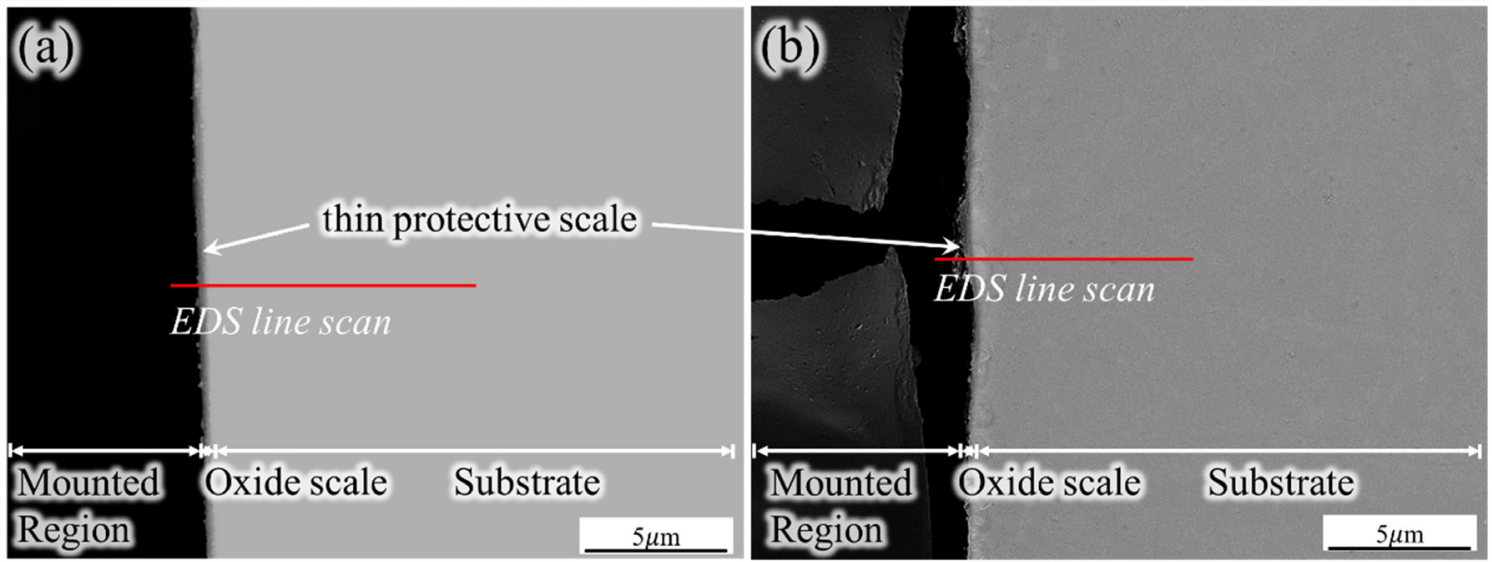

Fig. 5. Cross-sectional BSE micrographs of oxide scales oxidized in air for $60 \mathrm{~h}$ at $873 \mathrm{~K}$ (a), $973 \mathrm{~K}$ (c), and $1073 \mathrm{~K}$ (e) for the as-cast $12 \mathrm{Cr}-$ MoVW steel and $873 \mathrm{~K}$ (b), $973 \mathrm{~K}$ (d), and $1073 \mathrm{~K}$ (f) for the forged 12Cr-MoVW steel

tion of Ni near the interface between the inner oxide layer and substrate was observed in the EDS analysis, which indicates that the small black dots near the interface in Fig. 5 are due to the Ni segregation.

\section{Conclusion}

Based on the experimental results, the following conclusions can be drawn:

1. At low temperature $(\leq 973 \mathrm{~K})$, the forged $12 \mathrm{Cr}$-MoVW steel specimens exhibited extremely parabolic behavior and low oxidation rates; in contrast, at high temperature ( $>973 \mathrm{~K}$ ), both the as-cast and forged 12Cr-MoVW steel specimens exhibited breakaway behavior.

2. The fluctuation phenomenon of the initial slope of the curves of the forged $12 \mathrm{Cr}-\mathrm{MoVW}$ steel specimens is thought to be associated with the martensite phase.

3. The oxides of the forged $12 \mathrm{Cr}-\mathrm{MoVW}$ steel specimens formed at $973 \mathrm{~K}$ were uniformly dispersed compared with those of the as-cast state; the protective oxides are considered to be solid-solution compounds such as $(\mathrm{Fe}, \mathrm{Cr})_{2} \mathrm{O}_{3}$.

4. At high temperature $(1073 \mathrm{~K})$, both the as-cast and forged $12 \mathrm{Cr}-\mathrm{MoVW}$ steel specimens formed thick double oxide layers $(>50 \mu \mathrm{m})$ consisting of hematite and magnetite from the oxide/air interface to the oxide/substrate interface. 


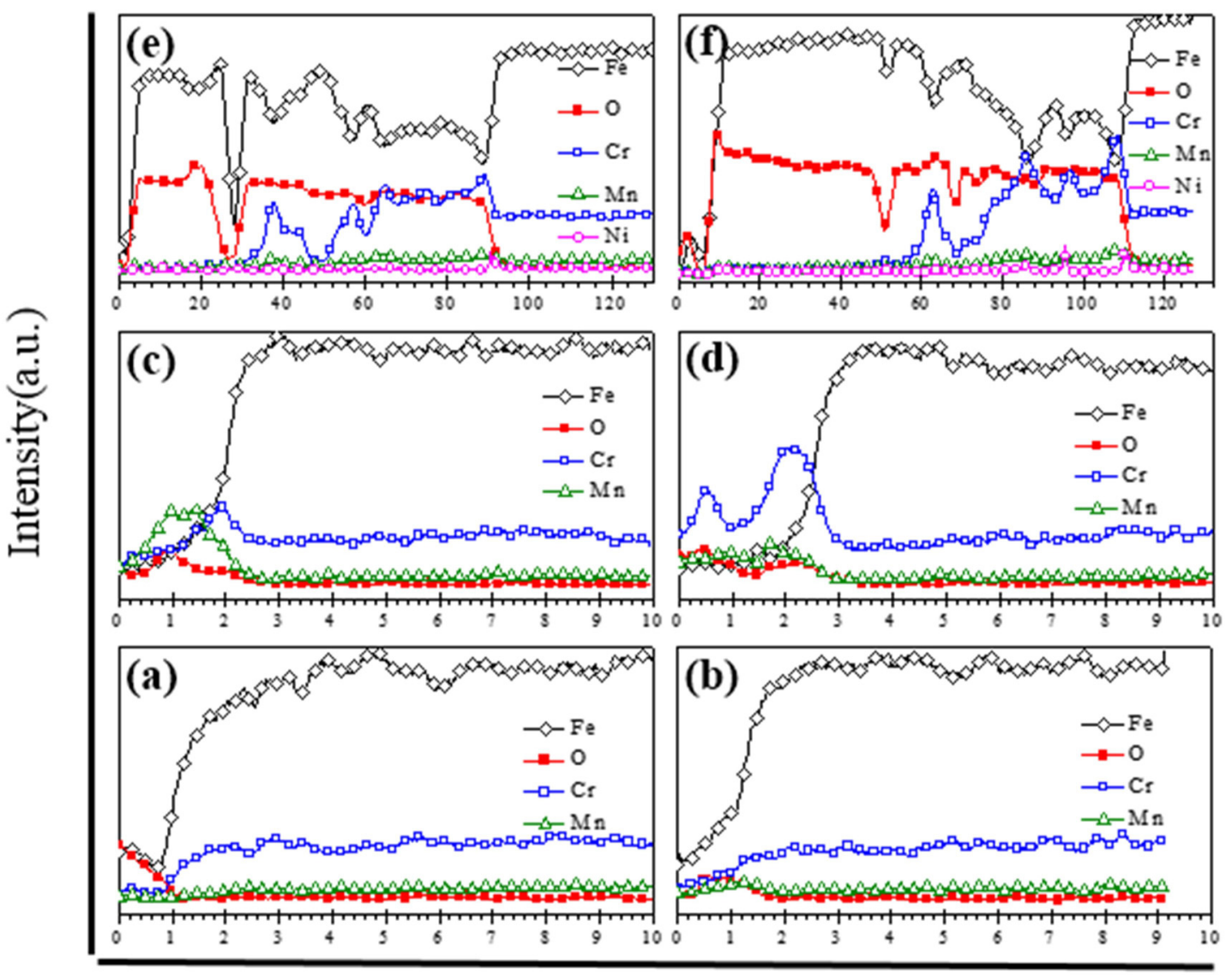

Distance $(\mu \mathrm{m})$

Fig. 6. EDS elemental analysis of the cross-sections in Fig. 5 after oxidation for $60 \mathrm{~h}$ in air at $873 \mathrm{~K}$ (a), $973 \mathrm{~K}$ (c), and $1073 \mathrm{~K}$ (e) for as-cast $12 \mathrm{Cr}-\mathrm{MoVW}$ steel and $873 \mathrm{~K}$ (b), $973 \mathrm{~K}$ (d), and $1073 \mathrm{~K}$ (f) for forged $12 \mathrm{Cr}-\mathrm{MoVW}$ steel

\section{Acknowledgements}

This work was supported by BK21PLUS, Social Enterprise Specialist Development Group.

\section{REFERENCES}

[1] R. Viswanathan, J. Nutting, Advanced Heat Resistant Steels for Power Generation, New York, 1999

[2] L. Jong-Pil, H. Ji-Hyun, P. Dong-Kyu, A. In-Shup, J. Korean Powder Metall. Inst. 22, 52-59 (2015).

[3] R. Viswanathan, W. Bakker, J. Mater. Eng. Perform. 10, 81-95 (2001).

[4] R. Viswanathan, J.F. Henry, J. Tanzosh, G. Stanko, J. Shingledecker, B. Vitalis, R. Purgert, J. Mater. Eng. Perform. 14, 281-292 (2005).

[5] M. Fujimitsu, ISIJ INT 41, 612-625 (2001).

[6] T. Sourmail, Mater. Sci. Tech. Lond. 17, 1-14 (2001).
[7] T. Fujita, ISIJ INT 32, 175-181 (1992).

[8] T. Maki, K. Akasaka, K. Okuno, I. Tamura, ISIJ INT 22, 253-261 (1982).

[9] A. Dehghan-Manshadi, P.D. Hodgson, J. Mater. Sci. 43, 6272-6277 (2008).

[10] W. Jei-Pil, L. Dong-Won, Y. Jung-Yeul, S. Shun-Myung, K. In-Soo, J. Korean Powder Metall. Inst. 20, 174-179 (2013).

[11] A.A. Tchizhik, T.A. Tchizhik, J. Mater. Process Tech. 77, 226-232 (1998).

[12] J. Ha, M. Tabuchi, H. Hongo, A. Toshimitsu Yokobori Jr, A. Fuji, Int. J. Pres. Ves. Pip. 81, 401-407 (2004).

[13] J. Das, S.M. Sivakumar, Eng. Fail Anal. 7, 347-358 (2000).

[14] B. Pieraggi, Oxid. Met. 27, 177-185 (1987)

[15] M. Levy, P. Farrell, F. Pettit, Corrosion 42, 708-717 (1986).

[16] J.R. Davis, ASM specialty handbook; heat-resistant materials, Cleveland, 1997.

[17] M.J. Graham, Corros. Sci. 37, 1377-1397 (1995).

[18] M.J. Graham, R.J. Hussey, Oxid. Met. 44, 339-374 (1995). 